\title{
Identifying the Gaps in HIV Prevention and Treatment During the COVID-19 Pandemic in Nigeria
}

\author{
Archibong Edem Bassey (ii ${ }^{1,}$, Lotenna Chidubem Olisaeloka ${ }^{2}$ and Yusuff Adebayo Adebisi (iD) 3 \\ ${ }^{1}$ Department of Public Health, University of Calabar, Calabar, Nigeria \\ ${ }^{2}$ Nnamdi Azikwe University Teaching Hospital, Nnewi, Anambra State, Nigeria \\ ${ }^{3}$ Faculty of Pharmacy, University of Ibadan, Ibadan, Nigeria \\ "Corresponding author: Department of Public Health, University of Calabar, Calabar, Nigeria. Email: basseyarchibong2015@gmail.com
}

Received 2020 September 19; Revised 2020 December 08; Accepted 2020 December 10.

\begin{abstract}
Context: To manage the COVID-19 pandemic, the Nigerian government has introduced travel restrictions to reduce the spread of the virus. However, this measure has caused numerous challenges in the accessibility and availability of HIV services (testing, prevention, and treatment) for patients. This study aimed to examine the delivery of HIV care services during the COVID-19 pandemic in Nigeria by analyzing the barriers to HIV care in recent years, weighing the impact of these barriers, and bridging the existing gaps by proposing practical solutions to maintain the patients' uninterrupted access to HIV services throughout the pandemic.

Evidence Acquisition: We searched Google Scholar, PubMed, and Science Direct databases, using the following MESH headings: "HIV", "COVID-19", and "Nigeria". The reviewed articles provided information on gaps and solutions for maintaining HIV services during the COVID-19 pandemic in Nigeria. The selected papers were all written in English, with no time restrictions. Also, further publications were identified from the reference lists of articles and reports via snowball sampling.

Results: The collected data in 2018 revealed that $67 \%$ of people living with HIV were aware of their disease status. Based on the results, $53 \%$ of people living with HIV were on antiretroviral treatment, and $42 \%$ of people living with HIV had viral suppression, based on the global 90-90-90 HIV targets. Ten barriers and gaps were identified in different aspects of HIV care delivery (prevention, testing, and treatment), and practical solutions were proposed to provide a more effective approach for ensuring the availability and accessibility of services during pandemics.

Conclusions: A unique and inter-sectoral approach is generally needed to address different barriers to the delivery of HIV care services during the COVID-19 pandemic. Also, funding of HIV care services is critical at this time. Based on the findings, HIV care services (prevention, testing, and treatment programs) cannot be postponed due to the COVID-19 outbreak, otherwise Nigeria may face a double pandemic.
\end{abstract}

Keywords: HIV, Nigeria, COVID-19

\section{Context}

In January 2020, the World Health Organization (WHO) declared coronavirus disease 2019 (COVID-19) as a public health emergency of international concern (PHEIC) (1). COVID-19 was declared as a pandemic on March 11, 2020, as it affected different countries across the world, including Nigeria and other African countries (2). On the other hand, over 75.7 million people have become infected with the human immunodeficiency virus (HIV) since the beginning of the HIV epidemic in the 1900's, and 38.0 million people were living with HIV in 2019. According to global statistics by the Joint United Nations Program on HIV/AIDS (UNAIDS) (3), COVID-19 continues to have devastating effects on the delivery of healthcare and HIV services across the world.

The first case of COVID-19 in Nigeria was reported by the Federal Ministry of Health in Lagos State on February 272020 (4). Since then, there has been a continuous rise in the incidence of COVID-19 across the country, as shown by the Nigeria Center for Disease Control (NCDC) dashboard (5). Considering the daily increase in the number of active cases of COVID-19, the question arises as to whether Nigeria is prepared to face a dual pandemic of HIV and COVID-19 $(6,7)$. Evidently, the COVID-19 pandemic interferes with HIV prevention and treatment services, as maintaining these services is of great importance during the pandemic $(8,9)$. It is obvious that travel restrictions, as a measure to manage the COVID-19 pandemic, have made it difficult for individuals to visit a healthcare facility for HIV testing (10). In this regard, Paul et al. explained how most individuals rely on public transportation to visit hospitals and clinics, 
as they live far from healthcare facilities. Therefore, travel restrictions have inevitably affected the burden of HIV (11).

\section{Evidence Acquisition}

In this study, we reviewed original research articles, reports, review articles, and other secondary sources to gather data. We aimed to identify the gaps and barriers to HIV prevention, testing, and treatment. An electronic search was conducted in Google Scholar, PubMed, and Science Direct databases, using the following MESH headings: "HIV", "COVID-19", and "Nigeria". The reviewed documents provided information on gaps and solutions for maintaining HIV services during the COVID-19 pandemic in Nigeria. All reviewed papers were written in English, with no time restrictions. Also, further publications were identified from the reference lists of relevant articles and reports through snowball sampling.

\section{Results}

\subsection{HIV and COVID-19 in Nigeria}

The data gathered in 2018 by UNAIDS revealed that $67 \%$ of persons living with HIV (PLHIV) knew their status, 53\% of them were on antiretroviral treatment (ART), and $42 \%$ of them were virally suppressed (12). These findings indicate the need for further effective measures to achieve the set targets, although progress may be slowed down by the ongoing COVID-19 pandemic. Overall, the COVID-19 outbreak has caused health challenges for PLHIV, leading to increased morbidity and even an immunocompromised status in these patients. Besides physical health, the emotional and social health of PLHIV has been affected by the pandemic, causing further disruptions in the delivery and availability of care and treatment services for $\operatorname{HIV}(13,14)$.

Although Nigeria has the biggest economy in Africa, the COVID-19 pandemic continues to cause major challenges and inequalities for Nigerian citizens, including health and economic problems (15). On the other hand, the Nigerian healthcare system has been overstretched due to limited resources, although health authorities have made major attempts to manage this pandemic. Nevertheless, the provision of adequate equipment and medications for health centers has not been addressed yet, posing a major challenge to the healthcare system of Nigeria (16).

\subsection{Analysis of Barriers and Gaps in the Delivery of HIV Services (Prevention, Testing, and Treatment)}

HIV programs have been negatively affected by the current COVID-19 pandemic due to ongoing disruptions in patients' access to HIV services. Overall, delivery of these services is influenced by different factors, such as aging, stigma, discrimination, religion, transportation restrictions, funding of human resources for healthcare delivery, health infrastructure, type of community (rural/urban), and domestic/sexual/gender violence. In 2005, with the approval of the United Nations General Assembly(UNGA) and World Health Assembly (WHA) $(17,18)$ to foster universal access to HIV prevention and treatment services, numerous initiatives were undertaken to tackle barriers to HIV prevention and treatment.

In countries, such as Nigeria, stigmatization, and discrimination against access to HIV services (prevention, testing, diagnostics, and treatment) continue to be major problems (19-21). According to the WHO reports (22), high mortality rates continue to be recorded in the elderly due to various diseases, including COVID-19 (23). Diagnosis of COVID-19 in an elderly person already living with HIV can be worrisome. In two studies on COVID-19 in immunocompromised elderly people $(24,25)$, immunosenescence was discovered as a factor leading to increased mortality among the elderly. Generally, immunosenescence refers to the gradual deterioration of the immune system due to advancing age (26). According to the Centers for Disease Control and Prevention (CDC) reports, older adults with an underlying disease (HIV), besides a weakened immune system, may be at an increased risk of infection with COVID-19 (27).

Generally, humans tend to blame others (e.g., foreigners traveling to or from the source country) for the spread of new diseases and outbreaks (28). Therefore, travel restrictions can be challenging for patients in times of crisis, especially for the PLHIV (29) and those who need facility-based HIV testing $(30,31)$. Due to home quarantine and travel restrictions, several cases of domestic violence, gender-based violence (GBD), and sexual abuse have been reported, mostly in women and young girls. The Lagos State alone recorded a 60\% increase in domestic violence, a $30 \%$ rise in sexual violence, and a $10 \%$ increase in physical child abuse during the lockdown period, which began in late March (32).

In April 2020, the United Nations Population Fund (UNFPA) (33) predicted a possible increase of $20 \%$ in domestic violence around the world in 2020 as a result of the COVID-19 pandemic; however, the impact of this pandemic on HIV services is not known yet. According to a study carried out in Sub-Saharan Africa by the Population Reference Bureau (34), GBV was an independent risk factor for HIV. Since young women are more likely to experience sexual and physical violence by an intimate partner, they are exposed to a high risk of infection, as they are unable to negotiate for safe sex or even seek treatment due to the presence of an abusive partner. Moreover, communities in rural ar- 
eas continue to be ignored in pandemic responses, while urban areas continue to take the spotlight (35). These rural areas normally have low levels of literacy, healthcare coverage, and access to healthcare services, all of which are possible barriers to care delivery, especially when dealing with neglected tropical diseases, such as HIV (36).

Establishment of the Prevention of Mother-to-Child Transmission of HIV (PMTCT) program, as a major strategy for HIV prevention, continues to face stigmatization, according to a recent qualitative study that explored the barriers to PMTCT interventions in Kano, the second most populous state in Nigeria (37). Overall, spirituality and religion continue to affect the community's perception of PLHIV, besides the PLHIV's views about themselves (38). These perceptions can have positive or negative outcomes (39). In Nigeria, religious beliefs have encouraged some PLHIV to stop using their ART medications in the hope of treatment through prayers by religious figures, without actually being tested for HIV. In some religious organizations, stigmatization toward PLHIV causes depression and other mental health issues, leading to medication termination and, finally, death (40).

Similarly, findings of another study revealed that healthcare workers perceived themselves to be highly at risk of COVID-19 infection, causing a decline in the delivery of healthcare services, including HIV services $(41,42)$. Also, financial constraints and unemployment continue to prevail during the COVID-19 pandemic, resulting in the patients' limited access to public transportation for receiving ART treatment and facility-based care (43). On the other hand, the global pledges and initiatives, such as the Global Fund, seem to be inadequate, as we are facing a different kind of pandemic (44).

\subsection{Effects of Barriers to Care for HIV on Public Health}

Jewell et al. (31) analyzed the impact of COVID-19related disruptions on HIV prevention and treatment services, using five HIV models (Imperial College London Model, Epidemiological Modeling Software, Optima HIV, HIV Synthesis, and Goals). After mathematical modeling, it was found that disruptions in ART delivery to PLHIV can cause an increase in mortality, while disruptions in HIV prevention programs (e.g., Peer Education, PREP, and use of condoms), besides closure of clinics for HIV testing and counseling, can increase the mortality rates significantly over time.

The WHO reported that between April and June 2020, almost 36 countries reported disruptions in the delivery of ART services (45). In these countries, 11.5 million people were receiving ART (45\% of total PLHIV on ART) (46). Moreover, according to the National Health Analytical Tool regarding the health service uptake during the COVID-19 pan- demic, a total of 505,903 individuals were counseled and tested for HIV in March, as compared to 311,786 individuals in April after the pandemic (47). The statistics continue to reflect how barriers to HIV services have great impacts on public health.

\subsection{Bridging the Gaps with Effective Solutions}

The availability of various testing options for HIV is a way to tackle barriers to the delivery of HIV testing services. The testing options for HIV include the finger-prick test and oral HIV self-testing. Due to the COVID-19 pandemic, HIV self-testing (home-based), in addition to HIV counseling, can be done over the phone instead of facility-based testing $(48,49)$. Generally, HIV self-testing is a confidential test, which has been recommended to reduce the stigma against facility-based testing (50). In this regard, a study was carried out in Nigeria using a youth participatory design approach, and an innovation Bootcamp model was proposed to develop HIV self-testing for young people. The results of this study indicated that HIV self-testing is essential for addressing the barriers to HIV testing and can serve as an entry point for the delivery of HIV prevention services.

Moreover, Ucheoma et al. (51) suggested that engaging young people through vocational skills training, community events, and reward systems can change the uptake of HIV prevention and testing not only among young people but also in the adult population of Nigeria. Considering the progress in HIV testing in Nigeria, the country cannot afford to regress. Although the development of HIV programs for pregnant women in low-resource settings is essential (52), young people should not be overlooked, as they are among the most at-risk populations (MARPS). Interventions, such as peer education, can increase the accessibility of HIV preventive medications, pre-exposure prophylaxis (PrEP), and post-exposure prophylaxis (PEP). Also, the implementation of mobile HIV counseling and testing (mHCT) can help tackle HIV in the event of another pandemic (53).

In schools, young people are less exposed to education about HIV and sexual/reproductive health (54). Therefore, improvement and implementation of the family life and HIV education (FLHE) programs can have great impacts on the fight against HIV/AIDS, especially among adolescents (55). The fight against HIV has indicated the need for empowering communities and involving them in response to the disease. Overall, human rights must not be compromised; all forms of stigma and discrimination must be eliminated; and vulnerable and marginalized groups must be supported (56). Moreover, the availability of treatment and test kits, infrastructure development, and timely re- 
muneration of healthcare workers are vital in times of crisis and pandemics.

In addition, essential preventive services, including HIV prophylaxis, antenatal and postnatal care, and HIV prophylaxis for newborns must be prioritized (57). Also, HIV services should be decentralized to rural areas, as HIV centers are normally located in inaccessible areas for rural populations (58). Moreover, in ART dispensing, clinicians must be open to extended multi-month ART (i.e., dispensing 3 - 6 months of antiretroviral supply), which can guarantee uninterrupted treatment and reduce coinfections, as well as the risk of COVID-19 transmission (59).

Today, countries are turning to telehealth and telemedicine, as most clinicians are on the frontline in the fight against COVID-19 and may not be able to prescribe HIV prophylaxis (PREP) (60); this shift is underway in Nigeria and can have positive impacts on HIV prevention. On the other hand, people's apathetic attitude toward the use of face masks in Nigeria is a critical issue (61). Evidence reported by the WHO (62) shows that the use of face masks can help reduce the risk of community transmission in areas affected by COVID-19 (63). The Nigeria Center for Disease Control (NCDC) (64) continues to provide regular information on different media platforms not only about the number of infected cases but also on how preventive measures, such as the use of face masks, can help overcome COVID-19.

In times of pandemics, men must be engaged in HIV prevention and treatment as supportive partners, clients of HIV services, and change agents. According to the information provided by the Population Council (65), addressing the barriers to men's timely engagement in HIV prevention and care is critical during the COVID-19 pandemic. After 100 days of response to COVID-19, the NCDC highlighted that effective collaboration is a key factor in this response (66). Therefore, we must view COVID-19 and HIV responses as a collaboration, not a competition, to develop strategies for the management of these pandemics.

Generally, collaboration in the community is an important phenomenon. HIV programs should bring men and women close together to determine how certain factors in the community make them vulnerable to HIV. Community dialogues continue to change the narrative of negative social and cultural norms affecting HIV (67). Also, prevention, as an important pillar of public health, can be more sustainable by ensuring a supportive environment that promotes health-seeking behaviors and ultimately reduces stigmatization against infected individuals (68).

In Nigeria, religious and spiritual beliefs influence the public's view about HIV patients and affect their interactions with their families and friends. Therefore, religious organizations can provide social support for society mem- bers, promote health-seeking behaviors, and discourage HIV-related risky behaviors. For example, the involvement of PLHIV in religious activities, such as religious programs (virtual programs due to social distancing), is an effective coping mechanism for improving their health and wellbeing (69).

In conclusion, the fast-growing field of HIV research should not be ignored in the heat of the COVID-19 pandemic. So far, historical approaches to disease outbreaks have been effective in the management of COVID-19, including social distancing, travel restrictions, and stigma reduction (70). Analysis of recent epidemics shows that strengthening the healthcare system (30) in terms of infrastructure, human resources, and budget allocation is indispensable in maintaining HIV services during the COVID19 outbreak.

\section{Conclusions}

Based on the present findings, a unique and intersectoral approach is needed to address the barriers to HIV service delivery during the COVID-19 pandemic. Also, funding of HIV services is highly critical at this time. Therefore, HIV services (i.e., prevention, testing, and treatment programs) cannot be postponed to solely focus on COVID-19, otherwise Nigeria will face a double pandemic.

\section{Footnotes}

Authors' Contribution: Study conception and design: A.B. and L.O.; analysis and interpretation of data: A.B. and Y.A.; drafting of manuscript: A.B. and L.O.; and critical revision: Y.A.

Conflict of Interests: The authors declare no conflict of interest.

Funding/Support: None.

\section{References}

1. WHO. Rolling updates on coronavirus disease 2020 (COVID-19). World Health Organization; 2020, [cited Nov 29]. Available from: https://www.who.int/emergencies/diseases/novel-coronavirus2019/events-as-they-happen.

2. WHO. Coronavirus disease (COVID-19) in China. World Health Organization; 2020. Available from: https://www.who.int/china/emergencies/ coronavirus-(covid-19).

3. Joint United Nations Programme on HIV/AIDS (UNAIDS). Global HIV \& AIDS statistics - 2020 fact sheet. 2020. Available from: https://www. unaids.org/en/resources/fact-sheet.

4. Nigerian Centre for Disease Control (NCDC). First case of coronavirus disease confirmed in Nigeria. 2020. Available from: https://ncdc.gov.ng/news/227/first-case- of-corona-virus-diseaseconfirmed-in-nigeria. 
5. Nigerian Centre for Disease Control (NCDC). COVID-19 dashboard 2020 2020. Available from: https://covid19.ncdc.gov.ng/.

6. Siddharth D, Yewande O, Obinna O. How well has Nigeria responded to COVID-19? The Brookings; 2020. Available from: https: //www.brookings.edu/blog/future-development/2020/07/02/howwell-has-nigeria-responded-to-covid-19/.

7. Parker A, Shaw J, Karamchand S, Lahri S, Schrueder N, Chothia MY, et al. HIV and SARS-CoV-2 co-infection: The diagnostic challenges of dual pandemics. S Afr Med J. 2020;110(6). doi: 10.7196/SAMJ.2020.v110i6.14825.

8. Jiang H, Zhou Y, Tang W. Maintaining HIV care during the COVID19 pandemic. Lancet HIV. 2020;7(5):e308-9. doi: 10.1016/s23523018(20)30105-3.

9. The Lancet HIV. When pandemics collide. Lancet HIV. 2020;7(5). e301. doi: 10.1016/s2352-3018(20)30113-2.

10. Ponticiello $M$, Mwanga-Amumpaire J, Tushemereirwe $P$, Nuwagaba $G$, King R, Sundararajan R. "Everything is a Mess": How COVID-19 is Impacting Engagement with HIV Testing Services in Rural Southwestern Uganda. AIDS Behav. 2020;24(11):3006-9. doi: 10.1007/s10461-02002935-w. [PubMed: 32451939]. [PubMed Central: PMC7246959].

11. Adepoju P. Tuberculosis and HIV responses threatened by COVID-19. Lancet HIV. 2020;7(5):e319-20. doi: 10.1016/s2352-3018(20)30109-0.

12. UNAIDS. Country fact sheets- Nigeria. 2020. Available from: https:// www.unaids.org/en/regionscountries/countries/nigeria.

13. Shiau S, Krause KD, Valera P, Swaminathan S, Halkitis PN. The Burden of COVID-19 in People Living with HIV: A Syndemic Perspective. AIDS Behav. 2020;24(8):2244-9. doi: 10.1007/s10461-020-02871-9. [PubMed: 32303925]. [PubMed Central: PMC7165075].

14. Torales J, O'Higgins M, Castaldelli-Maia JM, Ventriglio A. The outbreak of COVID-19 coronavirus and its impact on global mental health. Int J Soc Psychiatry. 2020;66(4):317-20. doi: 10.1177/0020764020915212. [PubMed: 32233719].

15. Human Rights Watch. Nigeria: Protect most vulnerable in COVID-19 response. 2020. Available from: https://www.hrw.org/news/2020/04/ 14/nigeria-protect-most-vulnerable-covid-19-response.

16. Akande-Sholabi W, Adebisi YA. The impact of COVID-19 pandemic on medicine security in Africa: Nigeria as a case study. The Pan African Medical Journal. 2020;35(Supp 2). doi: 10.11604/pamj.supp.2020.35.2.23671.

17. United Nations General Assembly. Resolution adopted by the general assembly on 16 September 2005. 2005, [updated 24 Oct 2005]. Available from: https://www.un.org/en/development/desa/population/ migration/generalassembly/docs/globalcompact/A_RES_60_1. pdf.

18. WHO. Fifty-ninth world health assembly. 2006. Available from: https://apps.who.int/gb/ebwha/pdf_files/WHA59-REC1/e/ WHA59 2006_REC1-en.pdf.

19. Monjok E, Smesny A, Essien EJ. HIV|AIDS-related stigma and discrimination in Nigeria: review of research studies and future directions for prevention strategies. Afr J Reprod Health. 2009;13(3):21-35. [PubMed: 20690259]. [PubMed Central: PMC2919838].

20. Iyamu IO. The findings of the national HIV/AIDS indicator and impact survey (NAIIS) presents an opportunity for a pivot in the HIV/AIDS response in Nigeria. GHAR; 2020. Available from: https://journals.mcmaster.ca/ ghar/article/view/2304.

21. Yahaya LA, Jimoh AAG, Balogun OR. Factors hindering acceptance of HIV|AIDS voluntary counseling and testing (VCT) among youth in Kwara State, Nigeria. Afr J Reprod Health. 2010;14(3):159-64.

22. WHO. Statement - Older people are at highest risk from COVID19, but all must act to prevent community spread. 2020. Available from: http://www.euro.who.int/en/health-topics/healthemergencies/coronavirus-covid-19/statements/statement-olderpeople-are-at-highest-risk-from-covid-19,-but-all-must-act-toprevent-community-spread.

23. Worldometer. Coronavirus update (live): COVID-19 virus outbreak. 2020. Available from: https://www.worldometers.info/coronavirus/ \#countries.

24. Oke GI, Fajobi TO, Elebesunu EE, Akpan SJ, Adebisi YA. COVID-19 in the elderly and the immunocompromised. Int J Health Life Sci. 2020;7(1). doi: 10.5812 /ijhls.105955.

25. Perrotta F, Corbi G, Mazzeo G, Boccia M, Aronne L, D’Agnano V, et al. COVID-19 and the elderly: insights into pathogenesis and clinical decision-making. Aging Clin Exp Res. 2020;32(8):1599-608. doi: 10.1007/s40520-020-01631-y. [PubMed: 32557332]. [PubMed Central: PMC7298699].

26. Chou JP, Effros RB. T cell replicative senescence in human aging. Curr Pharm Des. 2013;19(9):1680-98. doi: 10.2174/138161213805219711. [PubMed: 23061726]. [PubMed Central: PMC3749774].

27. CDC. What to know about HIV and COVID-19. 2020, [updated 2020 July 28]. Available from: https://www.cdc.gov/coronavirus/2019-ncov/ need-extra-precautions/hiv.html.

28. Jones DS. History in a crisis - lessons for Covid-19. $N$ Engl J Med. 2020;382(18):1681-3. doi: 10.1056/NEJMp2004361. [PubMed: 32163699].

29. UNAIDS. Travel restrictions. 2020. Available from: https://www.unaids. org/en/keywords/travel-restrictions.

30. Logie $\mathrm{CH}$, Turan JM. How do we balance tensions between COVID19 public health responses and stigma mitigation? learning from HIV research. AIDS Behav. 2020;24(7):2003-6. doi: 10.1007/s10461-02002856-8. [PubMed: 32266502]. [PubMed Central: PMC7137404].

31. Jewell BL, Mudimu E, Stover J, ten Brink D, Phillips AN, Smith JA, et al. Potential effects of disruption to HIV programmes in sub-Saharan Africa caused by COVID-19: results from multiple mathematical models. Lancet HIV. 2020;7(9):e629-40. doi: 10.1016/s2352-3018(20)30211-3.

32. Ejiro U; Premium times. Amidst covid-19 lockdown, Nigeria sees increased sexual and gender violence. 2020. Available from: https://pulitzercenter.org/reporting/amidst-covid-19-lockdownnigeria-sees-increased-sexual-and-gender-violence.

33. UNFPA. Impact of the COVID-19 pandemic on family planning and ending gender-based violence, female genital mutilation and child marriage. 2020. Available from: https://www.unfpa.org/sites/default/files/ resource-pdf/COVID-19_impact_brief_for_UNFPA_24_April_ 2020_1.pdf.

34. Population Reference Bureau. Gender-based violence increases risk of HIV/AIDS for women in Sub-Saharan Africa. 2020. Available from: https: //www.prb.org/gender-based-violence-hiv/.

35. Rural Health Information Hub. Healthcare access in rural communities. 2020. Available from: https://www.ruralhealthinfo.org/topics/ healthcare-access.

36. Hotez PI, Kamath A. Neglected tropical diseases in sub-saharan Africa: review of their prevalence, distribution, and disease burden. PLoS Negl Trop Dis. 2009;3(8). e412. doi: 10.1371/journal.pntd.0000412. [PubMed: 19707588]. [PubMed Central: PMC2727001].

37. Dirisu O, Eluwa G, Adams E, Torpey K, Shittu O, Adebajo S. "I think this is the only challenge... the stigma" Stakeholder perceptions about barriers to Antenatal care (ANC) and Prevention of mother-tochild transmission (PMTCT) uptake in Kano state, Nigeria. PLoS One. 2020;15(4). e0232028. doi: 10.1371/journal.pone.0232028. [PubMed: 32339180]. [PubMed Central: PMC7185580].

38. Vigliotti V, Taggart T, Walker M, Kusmastuti S, Ransome Y. Religion, faith, and spirituality influences on HIV prevention activities: A scoping review. PLoS One. 2020;15(6). e0234720. doi: 10.1371/journal.pone.0234720. [PubMed: 32544212]. [PubMed Central: PMC7297313].

39. Dalmida SG, Holstad MM, Dilorio C, Laderman G. The meaning and use of spirituality among African American women living with HIV|AIDS. West $J$ Nurs Res. 2012;34(6):736-65. doi: 10.1177/0193945912443740. [PubMed: 22566288]. [PubMed Central: PMC3978577].

40. Vera VA. Hiv infection, religion and spirituality in Nigerian community settings. Indian J Public Health Res Dev. 2020;11(4):750-3. doi: 10.37506/ijphrd.v11i4.7455. 
41. Ogolodom MP, Mbaba AN, Alazigha N, Erondu OF, Egbe NO, Golden I, et al. Knowledge, attitudes and fears of healthCare workers towards the corona virus disease (COVID-19) pandemic in South-South, Nigeria. Health Sci J Sp. 2020;1(2).

42. Bhagavathula AS, Aldhaleei WA, Rahmani J, Mahabadi MA, Bandari DK. Knowledge and perceptions of COVID-19 among health care workers: cross-sectional study. JMIR Public Health Surveill. 2020;6(2). e19160. doi: 10.2196/19160. [PubMed: 32320381]. [PubMed Central: PMC7193987].

43. Ridgway JP, Schmitt J, Friedman E, Taylor M, Devlin S, McNulty M, et al. HIV care continuum and COVID-19 outcomes among people living with HIV during the COVID-19 pandemic, Chicago, IL. AIDS Behav. 2020;24(10):2770-2. doi: 10.1007/s10461-020-02905-2. [PubMed: 32382823]. [PubMed Central: PMC7203502].

44. Friedman EA, Gostin LO, Maleche A, Nilo A, Foguito F, Rugege U, et al. Global health in the age of COVID-19: Responsive health systems through a right to health fund. Health Hum Rights. 2020;22(1):199-207. [PubMed: 32669801]. [PubMed Central: PMC7348449]

45. WHO. Disruption in HIV, hepatitis and STI services due to COVID-19. 2020. Available from: https://www.who.int/docs/default-source/hiv-hq/ disruption-hiv-hepatitis-sti-services-due-to-covid19.pdf.

46. WHO. Statement on the second meeting of the international health regulations (2005) emergency committee regarding the outbreak of novel coronavirus (2019-nCoV). 2020. Available from: https://www.who.int/news/item/30-01-2020-statement-onthe-second-meeting-of-the-international-health-regulations(2005)-emergency-committee-regarding-the-outbreak-of-novelcoronavirus-(2019-ncov).

47. Federal Ministry of Health. National health analytical tool showing health service uptake during the COVID-19 pandemic dashboard. 2020. Available from: https://msdat.fmohconnect.gov.ng/covid/index. html.

48. Nwaozuru U, Iwelunmor J, Ong JJ, Salah S, Obiezu-Umeh C, Ezechi O, et al. Preferences for HIV testing services among young people in Nigeria. BMC Health Serv Res. 2019;19(1):1003. doi: 10.1186/s12913-019-4847-x. [PubMed: 31881959]. [PubMed Central: PMC6935128].

49. Ritchwood TD, Selin A, Pettifor A, Lippman SA, Gilmore H, Kimaru L, et al. HIV self-testing: South African young adults' recommendations for ease of use, test kit contents, accessibility, and supportive resources. BMC Public Health. 2019;19(1):123. doi:10.1186/s12889-019-64024. [PubMed: 30696422]. [PubMed Central: PMC6352366].

50. Krause J, Subklew-Sehume F, Kenyon C, Colebunders R. Acceptability of HIV self-testing: a systematic literature review. BMC Public Health. 2013;13:735. doi: 10.1186/1471-2458-13-735. [PubMed: 23924387]. [PubMed Central: PMC3750621].

51. Nwaozuru U, Gbajabiamila T, Obiezu-Umeh C, Uzoaru F, Mason S, Tahlil K, et al. An innovation bootcamp model to develop HIV selftesting social enterprise among young people in Nigeria: a youth participatory design approach. Lancet Glob Health. 2020;8. S12. doi: 10.1016/s2214-109x(20)30153-4.

52. Ajayi A, Awopegba O, Owolabi E, Ajala A. Coverage of HIV testing among pregnant women in Nigeria: progress, challenges and opportunities. J Public Health (Oxf). 2019. doi: 10.1093/pubmed/fdz152. [PubMed: 31786595].

53. Ahmed S, Delaney K, Villalba-Diebold P, Aliyu G, Constantine N, Ememabelem $M$, et al. HIV counseling and testing and access-tocare needs of populations most-at-risk for HIV in Nigeria. AIDS Care. 2013;25(1):85-94. doi: 10.1080/09540121.2012.686597. [PubMed: 22709242]. [PubMed Central: PMC4884210].

54. Atibioke OP. Strengthening implementation structure for family life and HIV education in Nigeria. 2016. Available from: https://arfh-ng.org/strengthening-implementation-structure-forfamily-life-and-hiv-education-in-nigeria/

55. Igbokwe UL, Ogbonna CS, Ezegbe BN, Nnadi EM, Eseadi C. View- point on family Life and HIV education curriculum in Nigerian secondary schools. J Int Med Res. 2020;48(1):300060519844663. doi: 10.1177/0300060519844663. [PubMed: 31039671]. [PubMed Central: PMC7140188].

56. UNFPA. Evaluation of UNFPA support to the HIV response. 2020. Available from: https://www.unaids.org/en/keywords/unfpa-united-nationspopulation-fund.

57. The United States President's Emergency Plan for AIDS Relief (PEPFAR). PEPFAR's HIV response in the context of coronavirus disease 2019 (COVID-19). 2020. Available from: https://www.state.gov/pepfar/ coronavirus/.

58. Ogunkola IO, Adebisi YA, Imo UF, Odey GO, Esu E, Lucero-Prisno DE. Rural communities in Africa should not be forgotten in re sponses to COVID-19. Int J Health Plann Manage. 2020;35(6):13025. doi: 10.1002/hpm.3039. [PubMed: 32790138]. [PubMed Central: PMC7436649].

59. Bemelmans M, Baert S, Goemaere E, Wilkinson L, Vandendyck M van Cutsem G, et al. Community-supported models of care for people on HIV treatment in sub-Saharan Africa. Trop Med Int Health. 2014;19(8):968-77. doi: 10.1111/tmi.12332. [PubMed: 24889337].

60. Touger R, Wood BR. A review of telehealth innovations for HIV preexposure prophylaxis (PrEP). Curr HIV/AIDS Rep. 2019;16(1):113-9. doi: 10.1007/s11904-019-00430-z. [PubMed: 30701404].

61. Ogoina D. COVID-19: The need for rational use of face masks in Nigeria. Am J Trop Med Hyg. 2020;103(1):33-4. doi: 10.4269/ajtmh.20-0433. [PubMed: 32419693]. [PubMed Central: PMC7356454].

62. WHO. Statement on the second meeting of the International Health Regulation (2005). Emergency Committee regarding the out break of novel coronavirus (2019-nCoV). 2020. Available from: https://www.who.int/news/item/30-01-2020-statement-onthe-second-meeting-of-the-international-health-regulations(2005)-emergency-committee-regarding-the-outbreak-of-novelcoronavirus-(2019-ncov).

63. WHO. Advice on the use of masks in the context of COVID-19. 2020 Available from: https://www.who.int/publications/i/item/adviceon-the-use-of-masks-in-the-community-during-home-care-andin-healthcare-settings-in-the-context-of-the-novel-coronavirus(2019-ncov)-outbreak.

64. Nigeria centre for Disease Control(NCDC).Advisory on the use of masks by members of the public without respiratory symptoms. 2020. Available from: https://covid19.ncdc.gov.ng/media/files/UseOfMasks_ 1BdgzHH.pdf.

65. Pulerwitz J, Gottert A, Okal J, Mathur S. Evidence around engaging men in HIV prevention and treatment. Presentation at UNAIDS webinar. 2020 Nov 29. 2020

66. NCDC. 100 days of Nigeria's Covid-19 response. 2020. Available from: https://ncdc.gov.ng/news/253/100-days-of-nigeria-covid-19response.

67. Shoptaw S, Goodman-Meza D, Landovitz RJ. Collective call to action for HIV/AIDS community-based collaborative science in the Era of COVID-19. AIDS Behav. 2020;24(7):2013-6. doi: 10.1007/s10461-02002860-y. [PubMed: 32300993]. [PubMed Central: PMC7160820].

68. Krishnaratne S, Hensen B, Cordes J, Enstone J, Hargreaves JR. Interventions to strengthen the HIV prevention cascade: a systematic review of reviews. Lancet HIV. 2016;3(7):e307-17. doi: 10.1016/S23523018(16)30038-8. [PubMed: 27365205].

69. Szaflarski M. Spirituality and religion among HIV-infected individuals. Curr HIV/AIDS Rep. 2013;10(4):324-32. doi:10.1007/s11904-013-0175-7. [PubMed: 23996649]. [PubMed Central: PMC5302191].

70. PEPFAR. PEPFAR technical guidance in context of COVID-19 pandemic 2020. Available from: https://www.state.gov/wp-content/uploads/ 2020/07/07.01.2020-PEPFAR-Technical-Guidance-DuringCOVID.pdf. 